\title{
A mitochondrial mutation A4401G is involved in the pathogenesis of left ventricular hypertrophy in Chinese hypertensives
}

\author{
Hai-Yan Zhu ${ }^{1,2}$, Shi-Wen Wang ${ }^{*}$, Li Liu $^{3}$, Yan-Hua $\mathrm{Li}^{1}$, Rui Chen ${ }^{1}$, Lin Wang ${ }^{1}$ and \\ C James Holliman ${ }^{4}$
}

\begin{abstract}
${ }^{1}$ Institute of Geriatric Cardiology, General Hospital of Chinese PLA, Beijing, China; ${ }^{2}$ Emergency Department, General Hospital of Chineses PLA, Beijing, China; ${ }^{3}$ Department of National Center for Cardiovascular Disease, Cardiovascular Institute and Fuwai Hospital, Chinese Academy of Medical Sciences, Peking Union Medical College, Beijing, China;

${ }^{4}$ National Naval Medical Center, Bethesda, MD, USA
\end{abstract}

The left ventricular hypertrophy (LVH) is one of the most important organ damage targets in hypertension. Despite the involvement of multiple factors, the genetic factors have been shown to have an important function in the pathogenesis of LVH. The aim of our study was to evaluate the role of mitochondria in LVH for Chinese hypertensives. A systematic and extended mutational screening for the mitochondrial genome has been initiated in a large cohort of Chinese population by the Geriatric Cardiology Clinic at the Chinese PLA General Hospital, Beijing, China. Specific mutations within the mitochondria were further evaluated. Changes of total RNAs (tRNAs) were measured by northern blotting using nonradioactive digoxigenin (DIG)-labeled oligodeoxynucleotides specific for each RNA. Rates of oxygen consumption in intact cells were determined with av YSI 5300 oxygraph. Sequence analysis of mitochondrial DNA in one Chinese pedigree identified a novel A-G transition at position 4401 (A4401G) at the junction of tRNA ${ }^{\text {Met }}$ and tRNA ${ }^{\text {Gln }}$. The noncoding region mutation appeared to affect the processing of precursors in these mitochondrial tRNAs. The reduction in the rate of respiration and marked decreases in the steady-state levels of tRNA ${ }^{\mathrm{Met}}$ and tRNA ${ }^{\mathrm{Gln}}$ were detected in the cells carrying this mutation. The novel mutation was absent in 270 Chinese control patients. In conclusion, the noncoding mitochondrial sequence alteration (A4401G) alters mitochondrial function, implicating this mutation in the pathogenesis of LVH in Chinese hypertensives.

European Journal of Human Genetics (2009) 17, 172-178; doi:10.1038/ejhg.2008.151; published online 13 August 2008

Keywords: mitochondrion; left ventricular hypertrophy; hypertension

\section{Introduction}

Hypertension is one of the most common human sufferings, affecting approximately 1 billion individuals worldwide and 160 million in China. ${ }^{1,2}$ The left ventricular

*Correspondence: Dr S-W Wang, Institute of Geriatric Cardiology, General Hospital of Chinese PLA, 28 Fuxing Road, Beijing 100853, China. Tel: + 861066936761 ; Fax: + 861088270497 ;

E-mail: xiaoyanzibj301@163.com

Received 7 May 2008; revised 9 July 2008; accepted 11 July 2008; published online 13 August 2008 hypertrophy (LVH) is found in approximately $20-50 \%$ of hypertensives. It is a powerful and independent predictor of cardiovascular complications and death in patients with uncomplicated essential hypertension. $^{3-4}$ The LVH has been noted to be caused by single or multifactors including genetic and environmental factors. ${ }^{5-6}$ Of hereditary factors, the maternal transmissions of $\mathrm{LVH}$ have been implicated in some pedigrees in our unpublished data, suggesting that the mutation in mitochondrial DNA may be one of the molecular bases for this disorder. Actually, 
every heart beat consumes $2 \%$ of the total cellular ATP and $90 \%$ of its ATP is produced by mitochondrial oxidative phosphorylation. ${ }^{7}$ Thus, mitochondria may be implicated in the pathogenesis of multiple cardiovascular diseases, with regard to the basic functions of the organelle. ${ }^{8}$ Recently, several mtDNA mutations including A4295G and $A 4300 \mathrm{G}$ mutations in the mitochondrial tRNA ${ }^{\text {Ile }}$ gene have been identified in the Caucasian and African populations contributing to hypertrophic cardiomyopathy (HCM). ${ }^{9,10}$ HCM shares the same underlying pathology (myocyte disarray, interstitial fibrosis and artery wall thickness) with hypertension-related LVH. ${ }^{11}$ Taken together, it suggested that mitochondria may be involved in LVH in hypertensives. However, knowledge of the role of mitochondria in hypertension-associated $\mathrm{LVH}$ has been limited in Asian populations, particularly in Chinese population. With an effort to understand the etiology of hypertension-associated LVH, we recruited a large group of Chinese patients with hypertension at the Geriatric Cardiology Clinic at the Chinese PLA General Hospital, Beijing, China, from January 2006 to January 2007. Here we report the clinical, genetic, molecular and biochemical analysis of one three-generation Chinese pedigree with maternally transmitted LVH from the recruited group of patients.

\section{Materials and methods Patients}

We located a Chinese family through the Institute of Geriatric Cardiology, Chinese PLA General Hospital. Informed consent, blood samples, and clinical evaluations were obtained from all participating family members, under protocols approved by the Chinese PLA General Hospital ethics committee. Members of this pedigree were interviewed at length and their medical records were reviewed to identify medical histories of hypertension; including biochemical investigations, echocardiographic examinations and other clinical abnormalities. The 270 control DNA samples used for screening for the presence of mtDNA mutations were obtained from a panel of unaffected individuals from Chinese ancestry.

Hypertension evaluation and echocardiography exam Blood pressure measurements were taken in triplicate by a single experienced physician on three consecutive days, according to the Seventh Report of the Joint National Committee. ${ }^{1}$ Average systolic BP $\geq 140 \mathrm{mmHg}$ or diastolic $\mathrm{BP} \geq 90 \mathrm{mmHg}$ on 3 days was defined as hypertension. Echocardiographs were performed with M-mode and colorflow Doppler capabilities (GE Vingmed, System five, USA). The LVD dimension (LVDd), interventricular septal thickness (IVST) and the left ventricular posterior wall thickness (LVPWT) were measured at end-diastole and end-systole according to the American Society of Echocardiography recommendations. ${ }^{12}$ At the same time, systolic function including the left ventricular ejection fraction (EF), fractional shortening (FS), stroke volume (SV) and diastolic function including ratio of mitral peak velocity of early filling to mitral peak velocity of late filling (E/A ratio), isovolumic relaxation time (IVRT) were measured. Weight and height were measured, while the patients were fasting overnight and wearing only underwear.

The related empirically derived equations are as follows: $\mathrm{LV}$ mass $=1.04\left((\mathrm{IVST}+\mathrm{LVDd}+\mathrm{LVPWT})^{3}-\mathrm{LVDd}^{3}\right) 0.001-$ 13.6

$\mathrm{BSA}=0.006 \mathrm{H}+0.0128 \mathrm{~W}-0.1529$

$\mathrm{LVMI}=\mathrm{LVM} / \mathrm{BSA}$

Provisional criteria for the recognition of hypertrophy being the left ventricular index over $134 \mathrm{~g} / \mathrm{m}^{2}$ in men and above $110 \mathrm{~g} / \mathrm{m}^{2}$ in women. ${ }^{13}$

\section{Biochemical assays}

After a 12-h fast, $4 \mathrm{ml}$ venous blood was drawn to test biochemical assays including blood sugar, total cholesterol, triglyceride, high-density lipoprotein, low-density lipoprotein, blood urea nitrogen, urea acid and creatinine. The tests were performed using an automatic biochemistry analyzer (Hitach 7600DDP, Japan) and using the Roche biochemical reaction kits.

\section{Mitochondrial DNA analysis}

All genomic DNA were isolated from whole blood using a Promega Wizard ${ }^{\circledR}$ Genomic DNA Purification Kit (A1120, USA). One of the hottest spots of cardiovascular diseases ${ }^{14}$ located in tRNA ${ }^{\text {Leu(UUR) }}$ was first screened in the proband, using oligodeoxynucleotide $3796-4654 \mathrm{bp}$. Then PCR products were purified and subsequently analyzed by direct sequencing in an ABI 3700 automated DNA sequencer, using the BigDye Terminator Cycle sequencing reaction kit and analyzed with SeqWeb program GAP(GCG) according to the updated consensus Cambridge sequence. ${ }^{15}$ For the quantification of the A4401G mutation, oligodeoxynucleotides corresponding to mtDNA at positions $4336-4560 \mathrm{bp}$ were PCR, sequenced and subsequently digested with the restriction enzyme $B f a \mathrm{I}(0.5 \mathrm{U}$ per reaction) in all pedigrees (five mutants and four married-in-controls) to determine whether the mutant type was homoplasmic or heteroplasmic. An equal amount of various digested samples were electrophoresed through a 10\% polyacrylamide gel after staining with ethidium bromide. Laser densitometry was used to analyze the proportions of digested and undigested PCR products. The entire mitochondrial genome of mother-offspring units were PCR amplified in 24 overlapping fragments, by using sets of the light (L)-strand and the heavy $(\mathrm{H})$-strand oligonucleotide primers.

The mitochondrial DNA isolated from the control samples were scanned from 3796 to $4654 \mathrm{bp}$. 


\section{Cell cultures}

Lymphoblastoid cell lines were immortalized by transformation with the Epstein-Barr virus, as Miller and Lipman described. ${ }^{16}$ Cell lines derived from three maternal relatives (I-2, II-4, III-2) respectively, and three genetically unrelated control individuals (A2, A4, WZ100) were grown in RPMI 1640 medium (Invitrogen, Carlsbad, CA, USA), supplemented with $10 \%$ fetal bovine serum (FBS).

\section{Mitochondrial tRNA analysis}

Total mitochondrial RNA was obtained (Totally RNA kit; Ambion, Austin, TX, USA) from mitochondria isolated from lymphoblastoid cell lines $\left(\sim 4.0 \times 10^{8}\right.$ cells), as described previously. ${ }^{17}$ Three micrograms of total mitochondrial RNA was electrophoresed through a $8 \%$ polyacrylamide, 7-M urea gel in Tris-borate-EDTA buffer (TBE; after heating the sample at $65^{\circ} \mathrm{C}$ for $10 \mathrm{~min}$ ), and then electroblotted onto a positively charged nylon membrane (Roche Diagnostics, Mannheim, Germany) for the hybridization analysis with oligodeoxynucleotide probes. For the detection of tRNA ${ }^{\text {Met }}, \mathrm{tRNA}^{\mathrm{Gln}}, \mathrm{tRNA}^{\mathrm{Gly}}, \mathrm{tRNA}^{\mathrm{Lys}}$ and tRNA ${ }^{\text {Ser(UCN)}}$, the following nonradioactive digoxigenin (DIG)-labeled oligodeoxynucleotides specific for each RNA were used:

5'-TAGTACGGGAAGGGTATAACC-3' (tRNA $\left.^{\text {Met }}\right) ; 5^{\prime}$-CTAG

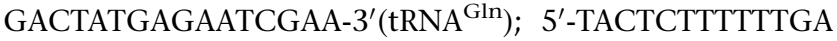
ATGTTGT-3' ${ }^{\prime}$ tRNA $^{\text {Gly }}$ ); 5'-TCACTGTAAAGAGGTGTTGG-3' $\left(\right.$ tRNA $\left.^{\text {Lys }}\right) ; 5^{\prime}$-ACAAAAAAGGAAGGAATCGA-3' $\left(\right.$ tRNA $\left.^{\text {Ser(UCN) }}\right)$.

Nonradioactive digoxigenin-labeled oligodeoxynucleotides were generated by using the DIG oligonucleotide tailing kit (Roche Diagnostics). Quantification of density in each band was carried out as detailed previously. ${ }^{18}$

\section{Oxygen consumption measurements}

Rates of oxygen consumption in intact cells were determined with a YSI 5300 oxygraph (Yellow Springs Instruments) on samples of $1 \times 10^{7}$ cells in $1.5 \mathrm{ml}$ of special Dulbecco's modified Eagel's medium lacking glucose, supplemented with $10 \%$ dialyzed FBS. ${ }^{19}$

\section{Computer analysis}

Continuous variables were expressed as mean \pm SD. Discrete variables in groups were expressed as frequency. Relations between continuous variables were assessed by the unpaired, two-tailed Student's $t$-test. Statistical analysis was performed using the software Stata 7.0 (StataCorp, College Station, TX, USA), $P<0.5$ was considered statistically different.

\section{Results}

\section{Clinical presentation}

The proband (I-2) was diagnosed as essential hypertension at the age of 64 years with the onset of dizziness and fainting for a year. She accepted echocardiographic screen-

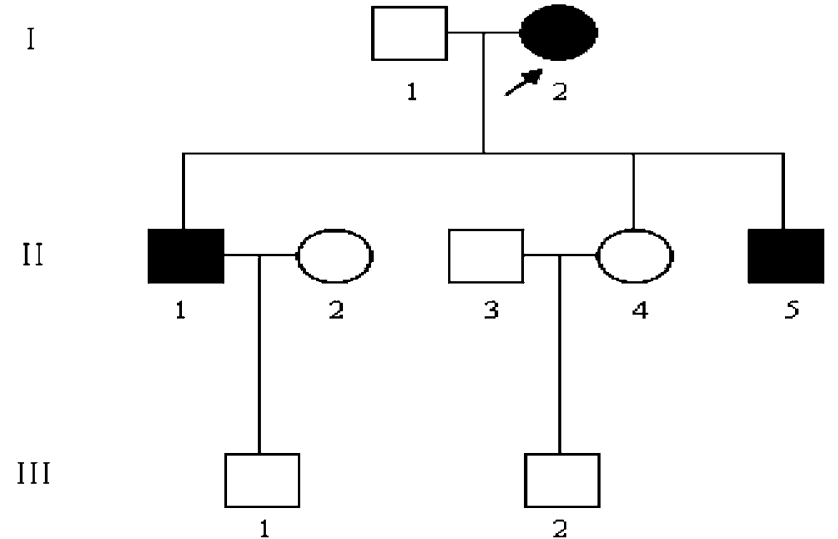

Figure 1 One three-generation Han Chinese pedigree with the left ventricular hypertrophy (LVH). Individuals suffered from LVH are indicated by the solid symbols. Open symbols represent normal left ventricular mass index. Generations are indicated on the left by roman numerals, and the numbers under the individuals represent identification numbers for each generation. Proband is indicated by arrow.

Table 1 Clinical features of maternal and non-maternal lineages

\begin{tabular}{|c|c|c|c|}
\hline & $\begin{array}{l}\text { Maternal } \\
\text { lineages }\end{array}$ & $\begin{array}{l}\text { Non-maternal } \\
\text { Lineages }\end{array}$ & P-value \\
\hline ge, years & $37 \pm 19.67$ & $38.75 \pm 22.47$ & 0.6213 \\
\hline $\begin{array}{l}\text { Female, (\%) } \\
\text { BMI, kg/m² }\end{array}$ & $\begin{array}{c}2(40) \\
25.29 \pm 6.15\end{array}$ & $21.68 \pm 3.29$ & $\begin{array}{c}1 \\
0.3272\end{array}$ \\
\hline $\mathrm{BSA}, \mathrm{m}^{2}$ & $1.80 \pm 0.34$ & $1.58 \pm 0.30$ & 0.4606 \\
\hline $\mathrm{SBP}, \mathrm{mmHg}$ & $110 \pm 21.21$ & $116.25 \pm 17.96$ & 0.5316 \\
\hline $\mathrm{DBP}, \mathrm{mmHg}$ & $76 \pm 24.08$ & 8.53 & 1 \\
\hline $\mathrm{HR}, \mathrm{bpm}$ & $69.4 \pm 7.53$ & $68.75 \pm 6.29$ & 0.9004 \\
\hline IVST, mm & $11.15 \pm 1.59$ & $8.76 \pm 0.25$ & $0.0497^{a}$ \\
\hline LVDD, $\mathrm{mm}$ & $51.5 \pm 4.79$ & $40.66 \pm 2.30$ & $0.0323^{a}$ \\
\hline LVPWT, mm & $10.32 \pm 0.921$ & $8.76 \pm 0.25$ & $0.0497^{a}$ \\
\hline IVDT, mm & \pm 0.01 & 0.01 & 0.1147 \\
\hline SF, \% & $37.82 \pm 7.34$ & $39.33 \pm 2.30$ & 1 \\
\hline$E F$, & $67 \pm 9.30$ & $72.33 \pm 2.51$ & 0.7237 \\
\hline $\begin{array}{l}\text { SV }, \mathrm{ml} \\
\mathrm{E} / \mathrm{A}\end{array}$ & $84.65 \pm 15.31$ & $76.66 \pm 5.77$ & 0.7213 \\
\hline $\mathrm{E} / \mathrm{A}$ & & & \\
\hline IVRT, s & 0.105 & 0.093 & 0.1345 \\
\hline LVMI, $\mathrm{g} / \mathrm{m}^{2}$ & $129.34 \pm 22.69$ & $70.87 \pm 3.11$ & $0.0339^{\mathrm{a}}$ \\
\hline FBS, $\mathrm{mmol} / \mathrm{l}$ & $5.14 \pm 0.67$ & $4.83 \pm 0.34$ & 0.6242 \\
\hline $\mathrm{TG}, \mathrm{mmol} / \mathrm{l}$ & $4.22 \pm 0.64$ & $3.76 \pm 0.43$ & 0.2207 \\
\hline $\mathrm{TC}, \mathrm{mmol} / \mathrm{l}$ & $1.19 \pm 0.62$ & $1.07 \pm 0.14$ & 0.8065 \\
\hline $\mathrm{HDL}, \mathrm{mmol} / \mathrm{l}$ & $1.33 \pm 0.30$ & $1.47 \pm 0.18$ & 0.3272 \\
\hline $\mathrm{LDL}, \mathrm{m}$ & $2.50 \pm 1.00$ & $2.38 \pm 0.61$ & 1 \\
\hline BUN, mmol/l & $4.59 \pm 0.72$ & $4.17 \pm 0.09$ & 0.4624 \\
\hline $\mathrm{UA}, \mu \mathrm{mmol} / \mathrm{l}$ & $275.14 \pm 97.47$ & $211.3 \pm 16.60$ & 0.3272 \\
\hline $\mathrm{CR}, \mu \mathrm{mmol} / \mathrm{I}$ & $71.9 \pm 19.14$ & $55.15 \pm 7.52$ & 0.1416 \\
\hline
\end{tabular}

BMI: body mass index, BSA: body surface area, SBP: systolic blood pressure, DBP: diastolic blood pressure, HR: heart rate, IVST: interventricular septal thickness, LVDD: left ventricular diastolic dimension, LVPWT: left ventricular posterior wall thickness, IVDT: interventricular septal thickness, SF: shortening fraction, EF: ejection fraction, SV: stroke volume, IVRT: isovolumic relaxation time, LVMI: left ventricular mass index, FBS: fasting blood sugar, TC: total cholesterol, TG: triglyceride, HDL: high-density lipoprotein, LDL: low-density lipoprotein, UA: urea acid, CR: creatine, BUN: blood urea nitrogen. ${ }^{a}$ Represent significantly different. 
a
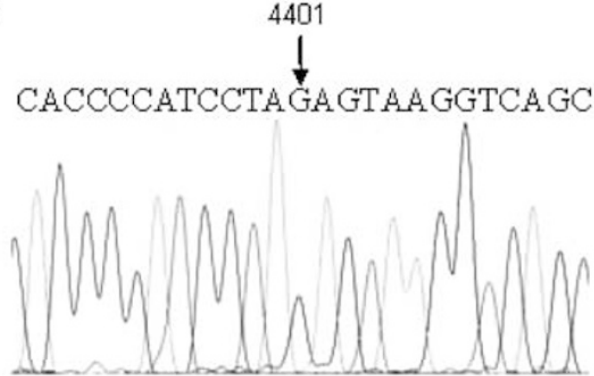

CACCCCATCCTAAAGTAAGGTCAGC

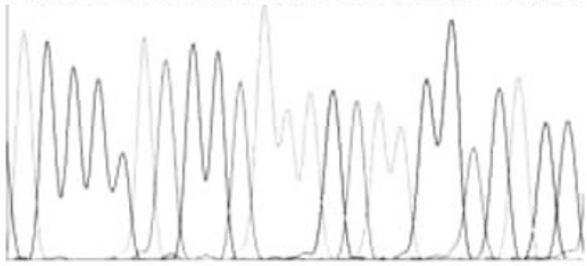

b

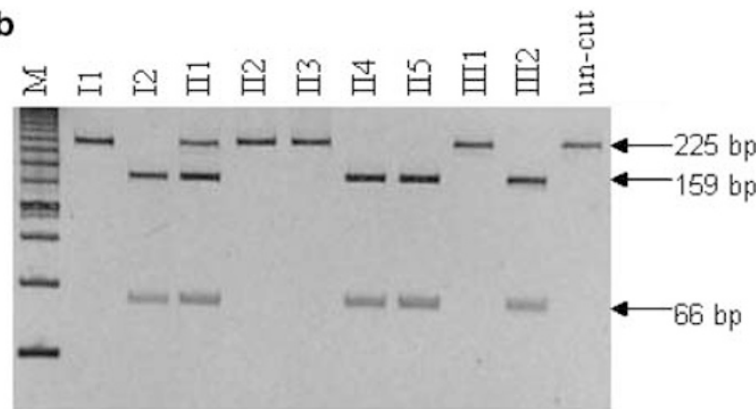

Figure 2 Identification and qualification of A4401G mutation in the mitochondrial gene. (a) Partial sequence chromatograms of mitochondrial gene from affected individual I-2 and a married-incontrol I-1. An arrow indicates the location of the base changes at position 4401. (b) Quantification of A4401G mutation in the mitochondrial gene of five mutants and four controls derived from the Chinese family. PCR products around the A4401G mutation were digested with $B f a$ l and electrophoresed through a $10 \%$ polyacrylamide gel after staining with ethidium bromide.

ing by the Institute of Geriatric Cardiology in the General Hospital of PLA at the age of 65 years. The LVH was identified by echocardiography. Interestingly, the maternal offspring of the proband (II-1, II-5) suffered from essential hypertension at the early ages of 36 and 17 years. Headache appeared to be the main symptom in the two individuals. Echocardiographic screening confirmed LVH in both of the descendants (Figure 1). However, in non-maternal lineages, none of the individuals was diagnosed as LVH according to clinical manifestations and echocardiogram. General information, echocardiographic parameters and biochemical values were analyzed in maternal and non-maternal lineages (Table 1). Although IVST ( $P$-value 0.0497), LVPWT $(P$-value 0.0323$)$, LVDd $(P$-value 0.0497$)$ and LVMI $(P$-value $0.0339)$ were significantly different between two groups, there were no differences in systolic (EF, FS, SV) and diastolic function (E/A, IVRT). Environmental factors including age, gender, BMI, fasting blood sugar, creatinine,
Table 2 mtDNA variants in the Chinese family

\begin{tabular}{|c|c|c|c|c|}
\hline Gene & Position & $\begin{array}{l}\text { Replacement } \\
(H / B / M / X)^{\mathrm{a}}\end{array}$ & $\begin{array}{l}\text { Conservation } \\
\text { reported }^{\text {b }}\end{array}$ & Previously \\
\hline \multirow[t]{8}{*}{ D-loop } & 73 & $A$ to $G$ & & Yes \\
\hline & 249 & $\operatorname{Del} A$ & & Yes \\
\hline & 310 & $\mathrm{~T}$ to $\mathrm{CTC}$ & & Yes \\
\hline & 489 & $\mathrm{~T}$ to $\mathrm{C}$ & & Yes \\
\hline & 16145 & $G$ to $A$ & & Yes \\
\hline & 16223 & $\mathrm{C}$ to $\mathrm{T}$ & & Yes \\
\hline & 16298 & $\mathrm{~T}$ to $\mathrm{C}$ & & Yes \\
\hline & 16519 & $\mathrm{~T}$ to $\mathrm{C}$ & & Yes \\
\hline \multirow[t]{2}{*}{$12 \mathrm{~S}$ rRNA } & 750 & $A$ to $G$ & & Yes \\
\hline & 1438 & A to $G$ & $\mathrm{~A} / \mathrm{A} / \mathrm{A} / \mathrm{G}$ & Yes \\
\hline $16 \mathrm{~S}$ rRNA & 2706 & $A$ to $G$ & $\mathrm{~A} / \mathrm{G} / \mathrm{A} / \mathrm{A}$ & Yes \\
\hline ND1 & 3552 & $\mathrm{~T}$ to $\mathrm{A}$ & & Yes \\
\hline tRNA & 4401 & A to $G$ & & No \\
\hline \multirow[t]{3}{*}{ ND2 } & 4715 & A to $G$ & & Yes \\
\hline & 4769 & $A$ to $G$ & & Yes \\
\hline & 5262 & $\begin{array}{l}\text { G to A } \\
\text { (Ala to Thr) }\end{array}$ & $\mathrm{A} / \mathrm{M} / \mathrm{I} / \mathrm{F}$ & Yes \\
\hline tRNA ${ }^{\text {Cys }}$ & 5821 & $\mathrm{G}$ to $\mathrm{A}$ & $\mathrm{G} / \mathrm{A} / \mathrm{A} / \mathrm{G}$ & Yes \\
\hline \multirow[t]{5}{*}{ CO1 } & 5993 & $C$ to $T$ & & No \\
\hline & 6338 & A to $G$ & & Yes \\
\hline & 6386 & $\mathrm{C}$ to $\mathrm{T}$ & & No \\
\hline & 7028 & $\mathrm{C}$ to $\mathrm{T}$ & & Yes \\
\hline & 7196 & $\mathrm{C}$ to $\mathrm{A}$ & & Yes \\
\hline \multirow[t]{3}{*}{ A6 } & 8584 & $\begin{array}{l}\text { G to } A \\
\text { (Ala to Thr) }\end{array}$ & $\mathrm{A} / \mathrm{V} / \mathrm{V} / \mathrm{I}$ & Yes \\
\hline & 8701 & $\begin{array}{l}\text { A to G } \\
\text { (Thr to Ala) }\end{array}$ & $\mathrm{T} / \mathrm{S} / \mathrm{L} / \mathrm{Q}$ & Yes \\
\hline & 8860 & $\begin{array}{l}\text { A to } G \\
\text { (Thr to Ala) }\end{array}$ & $\mathrm{T} / \mathrm{A} / \mathrm{A} / \mathrm{T}$ & Yes \\
\hline \multirow[t]{2}{*}{$\mathrm{CO} 3$} & 9540 & $\mathrm{~T}$ to $\mathrm{C}$ & & Yes \\
\hline & 9545 & $A$ to $G$ & & Yes \\
\hline \multirow[t]{2}{*}{ ND3 } & 10398 & $\begin{array}{l}\text { A to G } \\
\text { (Thr to Ala) }\end{array}$ & $\mathrm{T} / \mathrm{T} / \mathrm{T} / \mathrm{A}$ & Yes \\
\hline & 10400 & $\mathrm{C}$ to $\mathrm{T}$ & & Yes \\
\hline \multirow[t]{4}{*}{ ND4 } & 10873 & $\mathrm{~T}$ to $\mathrm{C}$ & & Yes \\
\hline & 11447 & $\begin{array}{l}\mathrm{G} \text { to } \mathrm{A} \\
\text { (Val to Met) }\end{array}$ & V/V/I/V & Yes \\
\hline & 11719 & $\mathrm{G}$ to $\mathrm{A}$ & & Yes \\
\hline & 11914 & $G$ to $A$ & & Yes \\
\hline \multirow[t]{2}{*}{ ND5 } & 12705 & $\mathrm{C}$ to $\mathrm{T}$ & & Yes \\
\hline & 13263 & $A$ to $G$ & & Yes \\
\hline ND6 & 14318 & $\begin{array}{l}\text { T to } C \\
\text { (Asn to Ser) }\end{array}$ & $\mathrm{N} / \mathrm{N} / \mathrm{D} / \mathrm{S}$ & Yes \\
\hline \multirow[t]{4}{*}{ CYTB } & 14783 & $\mathrm{~T}$ to $\mathrm{C}$ & & Yes \\
\hline & 15043 & $G$ to $A$ & & Yes \\
\hline & 15301 & $G$ to $A$ & & Yes \\
\hline & 15326 & $\begin{array}{l}\text { A to } G \\
\text { (Thr to Ala) }\end{array}$ & $\mathrm{T} / \mathrm{M} / \mathrm{I} / \mathrm{I}$ & Yes \\
\hline tRNA $^{T h r}$ & 15905 & T to $\mathrm{C}$ & $\mathrm{T} / \mathrm{T} / \mathrm{C} / \mathrm{T}$ & No \\
\hline
\end{tabular}

${ }^{a}$ Conservation of amino acid for polypeptides or nucleotide for rRNAs in human $(\mathrm{H})$, bovine $(\mathrm{B})$, mouse $(\mathrm{M})$ and xenopus laevis $(\mathrm{X})$.

${ }^{b}$ See the online mitochondrial genome database http://www. mitomap.org.

blood lipids and renal function did not exhibit differences, as seen in Table 1.

\section{Mitochondrial DNA analysis}

It was exiting to find a novel base pair mutation $A$ to $G$ located at the junction site of $\mathrm{tRNA}^{\mathrm{Met}}$ and $\mathrm{tRNA}^{\mathrm{Gln}}$ (Figure 2a). All mother-offspring units I-2, II-1, II-4, II-5 
and III- 2 were identified as carrying the novel mutation by purified PCR and sequencing, whereas the non-motheroffspring units, including I-1, II-2, II-3 and III-1, were without the specific mutation. A total of 270 control samples were identified without A4401G mutation. From Figure 2b, II-1 showed as heteroplasmic with approximate $60 \%$ mutant proportions, whereas I-2, II-4, II5 and III-2 displayed as homoplasmic. Over 24 overlapping fragments spanning through the entire mitochondrial DNA, I-2 was PCR amplified and sequenced and compared with the Cambridge consensus sequence. A series of nucleotide changes were detected (Table 2). All the nucleotide changes were verified in four additional maternal relatives of the family (II-1, II-4, II-5, III-2). There were 8 polymorphisms in the D-loop region, 2 variants in the $12 \mathrm{~S}$ rRNA gene, 1 variant in the $16 \mathrm{~S}$ rRNA gene, 25 variants in proteinencoding genes, G5821A in tRNA $^{\text {Cys }}$ and T15905C in tRNA $^{\text {Thr }}$. Except T15905C, these variants were previously identified in the control population.

\section{Marked decrease in the levels of mitochondrial tRNA $^{\text {Gln }}$ and tRNA ${ }^{\text {Met }}$}

The significant novel mutation A4401G located at the junction site of tRNA ${ }^{\text {Met }}$ and tRNA ${ }^{\text {Gln }}$ provided a clue that it may influence the processing of both tRNAs (Figure 3). To test the hypothesis, the steady-state level of tRNA ${ }^{\text {Met }}$ and tRNA $^{\text {Gln }}$ were isolated from the lymphoblastoid cell lines, separated on $8 \%$ polyacrylamide 7-M urea gels, electroblotted and hybridized with nonradioactive DIGlabeled oligodeoxynucleotide probes specific for tRNA ${ }^{\text {Met }}$ and $\mathrm{tRNA}^{\mathrm{Gln}}$. After stripping the blots, the DIG-labeled oligodeoxynucleotide probes specific for $\mathrm{tRNA}^{\text {Gly }}$ and tRNA $^{\text {Lys }}$, as representatives of the whole H-strand transcription unit and tRNA ${ }^{\mathrm{Ser}(\mathrm{UCN})}$, derived from the L-strand transcription unit were hybridized with the same blots for normalization purposes. As shown in Figure 4, the levels of tRNA $^{\text {Met }}$ and tRNA ${ }^{\text {Gln }}$ in the mutant cells were significantly reduced, relative to the controls. The average levels of tRNA $^{\text {Gln }}$ in mutant cells ranged between $\sim 63.73 \%$ of controls after normalization to tRNA ${ }^{\text {Gly }}$ ( $P$-value 0.0000$)$, $\sim 72.89 \%$ of controls after normalization to tRNA $^{\text {Lys }}$ ( $P$-value 0.0008$)$ and $\sim 59.79 \%$ of controls after normalization to $\mathrm{tRNA}^{\mathrm{Ser}(\mathrm{UCN})}(P$-value 0.0000$)$. Similarly, the a
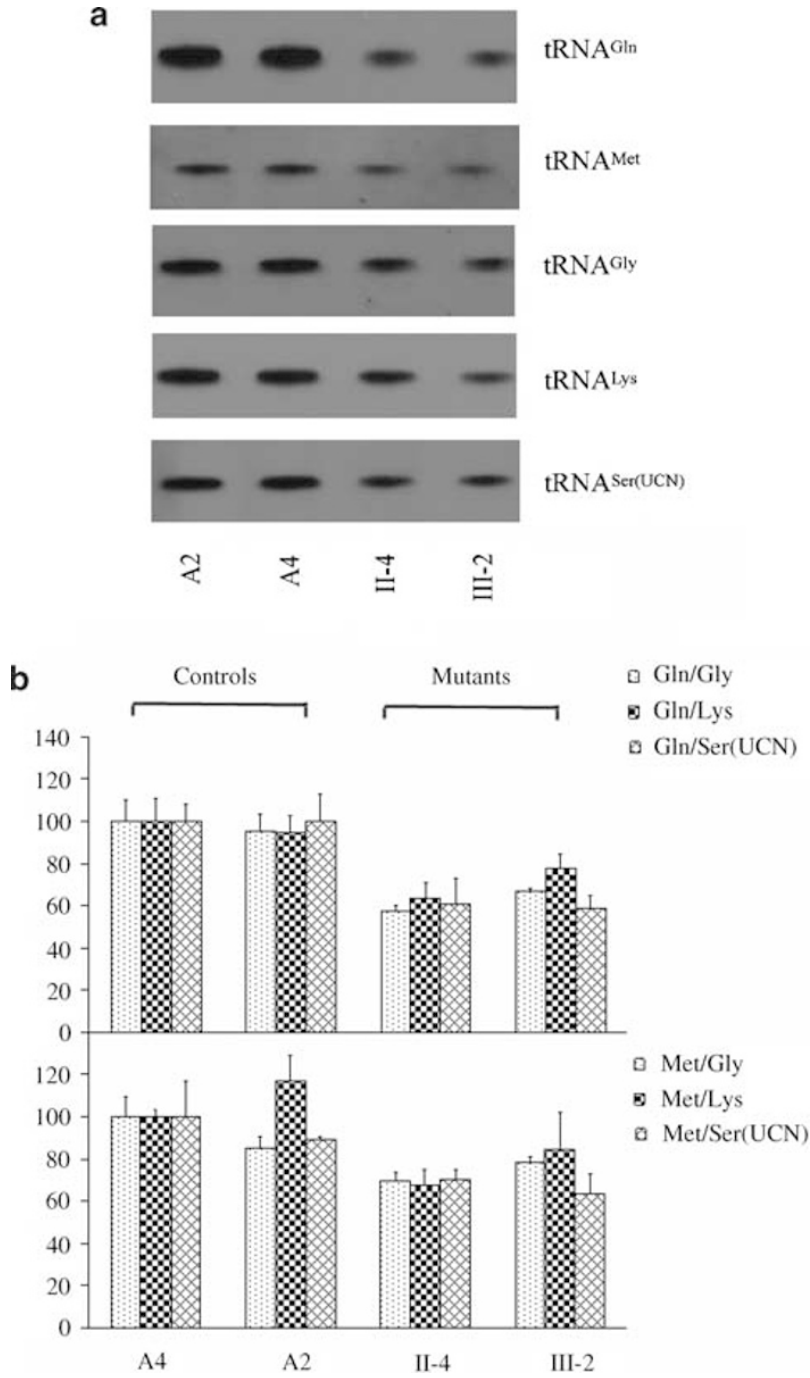

Figure 4 Northern Blot analysis of mitochondrial tRNA. (a) Equal amounts $(5 \mu \mathrm{g})$ of total mitochondrial RNA from various cell lines were electrophoresed through a denaturing polyacrylamide gel, electroblotted and hybridized with digoxigenin (DIG)-labeled oligonucleotide probes specific for the tRNA ${ }^{\mathrm{Met}}$ or tRNA ${ }^{\mathrm{Gln}}$ The blots were then stripped and rehybridized with DIG-labeled tRNA ${ }^{\text {Lys }}$, tRNA $^{\text {Ser(UCN) }}$ and tRNA $^{\text {Gly }}$, respectively. (b) Quantification of mitochondrial tRNA levels. Average relative tRNA ${ }^{\mathrm{Met}}$ and tRNA ${ }^{\mathrm{Gln}}$ content per cell normalized to the average content per cell of tRNA ${ }^{\text {Lys }}, \operatorname{tRNA}^{\mathrm{Ser}(\mathrm{UCN})}$ and tRNA ${ }^{\mathrm{Gly}}$ in two control cell lines (A2, A4) and two mutant cell lines (II-4, III-2) carrying the A4401G mutation.

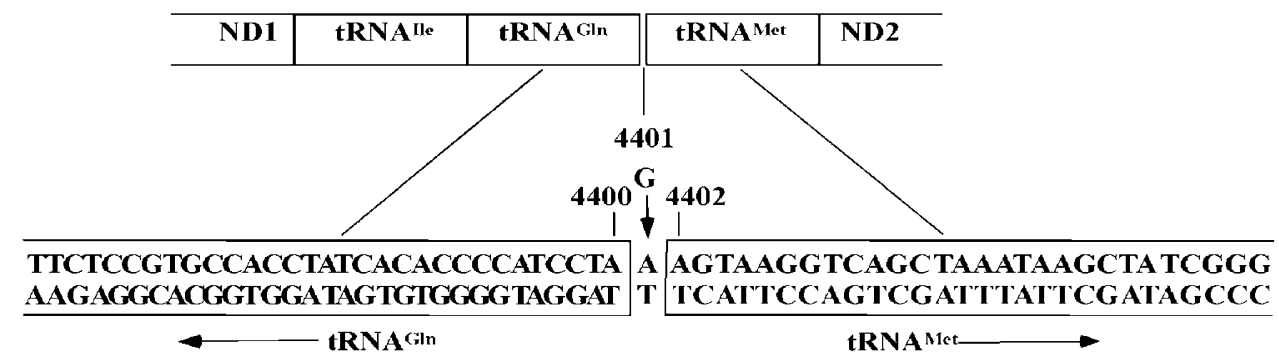

Figure 3 The position of $\mathrm{A} 4401 \mathrm{G}$ mutation at the junction of mitochondrial tRNA ${ }^{\mathrm{Met}}$ and $\mathrm{tRNA} \mathrm{Gln}^{\mathrm{Gln}}$. 
average levels of tRNA ${ }^{\text {Met }}$ varied from $\sim 79.78 \%$ ((after normalization to tRNA $\left.^{\text {Gly }}\right)(P$-value 0.0037$\left.)\right), \sim 69.92 \%$ ((after normalization to tRNA $\left.{ }^{\text {Lys }}\right)$ ( $P$-value 0.0021$\left.)\right)$, to $\sim 70.92 \%$ ((after normalization to tRNA ${ }^{\text {Ser }(\mathrm{UCN})}$ ( $P$-value $0.0000)$ ) of controls.

\section{Decrease in oxygen consumption rate}

To measure the endogenous respiration rates of mutant and control cell lines, oxygen consumption rates in intact cells derived from lymphoblastoid cell lines were investigated using the classic method described previously. ${ }^{16}$ The oxygen consumption rate in the mutant cells decreased as compared to the average level of control cell lines ( $P$-value 0.0001$)$ (Figure 5 , Table 3$). O f$ mutant cell lines, the symptomatic patient exhibited a remarkable decrease of $37.37 \%$ compared with the other two asymptomatic patients with 15.55 and $8.8 \%$ respectively ( $P$-value 0.0007$)$. However, no significant difference between asymptomatic individuals with the mutation (II-4 and III-2) was detected (P-value 0.0161).

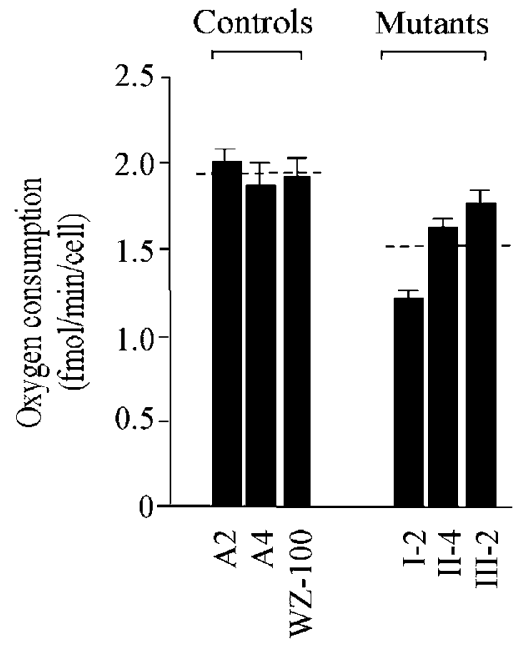

Figure 5 Respiration assays. Average rates of endogenous oxygen consumption per cell measured in different lymphoblastoid cell lines are shown, with error bars representing standard errors of the mean (SEM). The six determinations were carried out for each cell line. The horizontal dashed lines represent the average value for each group.

\section{Discussion}

The clinical, biochemical and genetic survey showed that the three-generation Han Chinese family followed the rule of maternal inheritance. Maternal offsprings were identified carrying the novel mutation A4401G. However, the novel mutation was absent in non-mother-offspring units and 270 blood-unrelated controls. Interestingly, three of five mother-offspring units exhibited a consistent cardiovascular phenotype, hypertension-associated LVH. Environmental factors failed to reveal any difference within maternal and non-maternal lineages. In particular, main variables including gender, age, blood pressure and BMI contributing a lot to ventricular geometrics were at the same level. ${ }^{20,21}$ Herein, it was presumed that hereditary factors involved in the course of LVH in the Chinese Han family. The maternal transition implied the involvement of mitochondria in the pathogenesis of LVH in this Chinese three-generation lineage. ${ }^{22}$

Except the novel A4401G mutation, there were no notable mutations contributing to LVH by entire mitochondrial genome sequencing of the mother-offspring units. The variants in noncoding genes were previously identified in the control population. None of them was associated with hypertension-related ventricular hypertrophy according to the detailed description on the website http://www.mitomap.org. Although 10 amino acid substitutions caused by corresponding mtDNA variants occurred in different rRNAs and polypeptides, further evaluation by phylogenetic analysis of these variants and sequences from other organisms including mouse, bovine and xenopus laevis showed no evolutionary conservation.

The reduction of $\mathrm{tRNA}^{\text {Met }}$ and $\mathrm{tRNA}^{\mathrm{Gln}}$ in the mutant cells showed that the A4401G mutation at the junction site of tRNA $^{\text {Met }}$ and tRNA $^{\text {Gln }}$ affected the processing of both tRNAs and thus has a significant influence on the steady level of tRNAs. Additionally, the oxygen consumption rate was found remarkably decreased in cell lines carrying the mutation ( $P$-value 0.0001). In particular, symptomatic patient harboring the mutation exhibited much more reduction in the oxygen consumption rate as compared to asymptomatic patients harboring the mutation $(P$-value 0.0007). It follows the rule of pathogenic mitochondrial mutations that symptoms arise once mutations over certain threshold and lead to impaired mitochondrial

Table 3 Oxygen consumption rate in lymphoblastoid cell lines carrying A4401G mutation and the control cell lines, relative to mean of controls (\%)

\begin{tabular}{|c|c|c|c|c|c|}
\hline \multicolumn{3}{|c|}{ Mutation cell lines $^{\mathrm{a}}$} & \multicolumn{3}{|c|}{ Control cell lines } \\
\hline $62.63 \pm 3.51$ & $84.45 \pm 0.7$ & $91.32 \pm 4.02$ & $103.61 \pm 7.51$ & $97.08 \pm 16.8$ & $93.1 \pm 15.01$ \\
\hline
\end{tabular}

${ }^{a} P$-value 0.0001 , significant difference between the mutant cell lines and the controls.

${ }^{\mathrm{b}} P$-value 0.0007 , significant difference between mutant cell lines: symptomatic mutation (I-2) and asymptomatic mutations (II-4, III-2).

${ }^{\mathrm{C}} P$-value 0.0161 , no significant difference between asymptomatic mutant cell lines (II4 and III2). 
protein synthesis, as well as a severe respiratory chain deficiency. $^{22}$ The mutation A4401G within mitochondria influenced the function of the mitochondria in the perspective of steady levels of tRNAs and oxygen consumption rates that may affect the expression of protein in the end. Oxygen consumption is a classical means of assessing energy expenditure, one component of energy balance. ${ }^{23}$ Cells and organisms are able to trigger an adaptive response to hypoxic conditions that is aimed to help them to cope with these threatening conditions. Failing to keep the balance of oxygen consumption and production causes a series of cardiovascular disorders of heart failure, arrhythmia, ventricular hypertrophy, as described previously. ${ }^{24-25}$

A variety of phenotype and age of onset were found in the mother-offspring units. Otherwise, two of maternal lineages did not exhibit hypertension-associated LVH, young age and healthy living styles that help to elucidate the phenotype in part. Incomplete penetrance arising from mitochondrial mutations is well described and has been attributed to nuclear genome and/or environmental modifiers according to meta-analysis of online database. ${ }^{26}$

In conclusion, the noncoding mitochondrial sequence alteration (A4401G) alters mitochondrial function, implicating this mutation in the pathogenesis of LVH in Chinese hypertensives. This was the first step we marched to investigate the mitochondrial role in hypertension-related LVH in family-based Chinese hypertensives, and further study was necessary to elucidate the synergetic role of mitochondrial and nucleic genomes in the pathogenesis of LVH.

\section{Acknowledgements}

We thank all the participants of investigation, sophisticated clinicaldata collecting of Chunlin Zeng. This study was supported by grants from Chinese National Natural Science Funds (Capital Developmental Grant-Key Project No. 2003-2019 to SWW).

\section{References}

1 Chobanian AV, Bakris GL, Black HR et al: The Seventh Report of the Joint National Committee on Prevention, Detection, Evaluation, and Treatment of High Blood Pressure: the JNC 7 report. JAMA 2003; 289: 2560-2572.

2 LS. L: 2005 Guidelines for prevention and treatment of hypertension in China, 1st edn Beijing: People's medical publishing house, 2007, pp 1-8.

3 Julien J, Tranche C, Souchet T: Left ventricular hypertrophy in hypertensive patients. Epidemiology and prognosis. Arch Mal Coeur Vaiss 2004; 97: 221-227.

4 Krauser DG, Devereux RB: Ventricular hypertrophy and hypertension: prognostic elements and implications for management. Herz 2006; 31: 305-316.

$5 \mathrm{Fu} \mathrm{C}$, Wang H, Wang S et al: Association of beta (1)-adrenergic receptor gene polymorphisms with left ventricular hypertrophy in human essential hypertension. Clin Biochem 2008; 41: $773-778$.

6 Walther T, Tschope C, Sterner-Kock A et al: Accelerated mitochondrial adenosine diphosphate/adenosine triphosphate transport improves hypertension-induced heart disease. Circulation 2007; 115: 333-344.

7 Schapira AH: Mitochondrial disease. Lancet 2006; 368: 70-82.

8 Hirano M, Davidson M, DiMauro S: Mitochondria and the heart. Curr Opin Cardiol 2001; 16: 201-210.

9 Merante F, Myint T, Tein I, Benson L, Robinson BH: An additional mitochondrial tRNA(Ile) point mutation (A-to-G at nucleotide 4295) causing hypertrophic cardiomyopathy. Hum Mutat 1996; 8 : 216-222.

10 Casali C, Santorelli FM, D'Amati G, Bernucci P, DeBiase L, DiMauro S: A novel mtDNA point mutation in maternally inherited cardiomyopathy. Biochem Biophys Res Commun 1995; 213: $588-593$.

11 Safar ME, Czernichow S, Blacher J: Obesity, arterial stiffness, and cardiovascular risk. Am Soc Nephrol 2006; 17 (4 Suppl 2): S109-S111.

12 Sahn DJ, DeMaria A, Kisslo J, Weyman A: Recommendations regarding quantitation in M-mode echocardiography: results of a survey of echocardiographic measurements. Circulation 1978; 58: 1072-1083.

13 Devereux RB: Detection of left ventricular hypertrophy by M-mode echocardiography. Anatomic validation, standardization, and comparison to other methods. Hypertension 1987; 9: II19-II26.

14 Silvestri G, Santorelli FM, Shanske S et al: A new mtDNA mutation in the tRNA(Leu(UUR)) gene associated with maternally inherited cardiomyopathy. Hum Mutat 1994; 3: 37-43.

15 Anderson S, Bankier AT, Barrell BG et al: Sequence and organization of the human mitochondrial genome. Nature 1981; 290: 457-465.

16 Miller G, Lipman M: Release of infectious Epstein-Barr virus by transformed marmoset leukocytes. Proc Natl Acad Sci USA 1973; 70: $190-194$.

17 King MP, Attardi G: Post-transcriptional regulation of the steadystate levels of mitochondrial tRNAs in HeLa cells. J Biol Chem 1993; 268: 10228-10237.

18 Enriquez JA, Chomyn A, Attardi G: MtDNA mutation in MERRF syndrome causes defective aminoacylation of tRNA(Lys) and premature translation termination. Nat Genet 1995; 10: 47-55.

19 King MP, Attardi G: Human cells lacking mtDNA: repopulation with exogenous mitochondria by complementation. Science 1989; 246: 500-503.

20 de Simone G, Pasanisi F, Contaldo F: Link of nonhemodynamic factors to hemodynamic determinants of left ventricular hypertrophy. Hypertension 2001; 38: 13-18.

21 Lekakis JP, Zakopoulos NA, Protogerou AD et al: Cardiac hypertrophy in hypertension: relation to 24 -h blood pressure profile and arterial stiffness. Int I Cardiol 2004; 97: 29-33.

22 Zhu HY, Wang SW: Mitochondria and left ventricular hypertrophy. J Geriatr Cardiol 2008; 5: 50-59.

23 Ritz P, Berrut G: Mitochondrial function, energy expenditure, aging and insulin resistance. Diabetes Metab 2005; 2: 5S67-5S73.

24 Clayton D, Williams R, Liang I: Meeting highlights: mitochondrial DNA mutations and cardiomyopathy, heart failure, and ischemic heart disease. Circulation 1995; 92: 2022-2023.

25 Laine H, Katoh C, Luotolahti $M$ et al: Myocardial oxygen consumption is unchanged but efficiency is reduced in patients with essential hypertension and left ventricular hypertrophy. Circulation 1999; 00: 2425-2430.

26 Carelli V, Giordano C, d'Amati G: Pathogenic expression of homoplasmic mtDNA mutations needs a complex nuclearmitochondrial interaction. Trends Genet 2003; 19: 257-262. 